\title{
A Novel Model-Based Questionnaire Based on Low-Dose CT Screening Data for Chronic Obstructive Pulmonary Disease Diagnosis in Shimane, Japan
}

\author{
Akari Tanino $\mathbb{D}^{\prime}$ \\ Toshihiko Kawamura ${ }^{2}$ \\ Megumi Hamaguchi' \\ Ryosuke Tanino (D) \\ Mika Nakao' \\ Takamasa Hotta $\mathbb{D}^{\prime}$ \\ Yukari Tsubata (iD) \\ Shunichi Hamaguchi ${ }^{1}$ \\ Takeshi Isobe' \\ 'Department of Internal Medicine, \\ Division of Medical Oncology \& \\ Respiratory Medicine, Shimane University \\ Faculty of Medicine, Izumo, Shimane, \\ Japan; ${ }^{2}$ Division of Medical Informatics, \\ Shimane University Faculty of Medicine, \\ Izumo, Shimane, Japan
}

Purpose: Although there have been many reports on the use of respiratory function tests and questionnaires for creating chronic obstructive pulmonary disease (COPD) questionnaires, there have been no reports on the effectiveness of questionnaires using computed tomography (CT) screening data. We aimed to validate the International Primary Care Airways Group (IPAG) questionnaire and to propose a novel COPD screening questionnaire based on the CT screening data of Japanese participants.

Patients and Methods: Low-dose CT screening was performed for early detection of lung cancer and COPD since 2009 in Shimane, Japan, and clinical information was collected using an original questionnaire that included all the IPAG questionnaire items and eight additional items (for eg, on dyspnea) during CT screening. Participants with emphysema, smoking history, and respiratory symptoms were instructed to undergo a respiratory function test. The participants with the forced expiratory volume in one second $\left(\mathrm{FEV}_{1}\right)$ /forced vital capacity $(\mathrm{FVC})<0.7$ on the respiratory function test were diagnosed with COPD, and 11,458 participants underwent CT screening from 2013 to 2016 and were enrolled and filtered using $<22.5$ pack-years. Data from 3252 participants were selected for the final analysis. The receiver operating characteristic curve determined the best cutoff points for discriminating patients with COPD. The efficacy of the questionnaire items was determined using logistic regression analysis.

Results: The best cutoff point for the Japanese IPAG questionnaire was 23. The logistic regression analysis revealed significant differences in the question items of "age", "packyear", "cough", "phlegm", and "feeling of dyspnea". COPD-CT questionnaire was developed based on the CT screening data. The COPD predicted value was determined using the regression model obtained in this study.

Conclusion: The IPAG questionnaire had low specificity for discriminating COPD in Japanese patients. A novel questionnaire (COPD-CT) and the COPD predicted value based on the CT screening data was developed.

Keywords: Japanese population, validation, pack-years, prediction model

\section{Introduction}

Chronic obstructive pulmonary disease (COPD) is a respiratory disease that can be prevented from progressing or exacerbating with proper management. The prevalence of COPD outside of Japan is approximately 10-20\% according to the results of multinational research projects. ${ }^{1-4}$ In Japan, the prevalence is $8.6 \%{ }^{5}$, which is 
slightly less than other countries. Notably, pack-years are highly related to COPD prevalence; 20 pack-years of smoking have $19 \%$ prevalence, ${ }^{3}$ and 60 or more packyears of smoking have approximately $70 \%$ of COPD prevalence. ${ }^{6}$ Early detection of COPD is vital because COPD is associated with an increased risk of lung cancer. $^{7-9}$ However, respiratory function tests, which are essential for the diagnosis of COPD in the primary care setting, have not been widely used, and a system for early COPD detection has not yet been established. ${ }^{10,11}$ Approximately $90 \%$ of patients with COPD remain undiagnosed. $^{5}$

A simple questionnaire was suggested as a useful noninvasive method for predicting high-risk groups for $\mathrm{COPD}^{12}$ and for the early detection of COPD. Price et al recruited 818 smokers in the UK and USA and proposed a questionnaire for identifying COPD (IPAG questionnaire). ${ }^{13,14}$ It was published in the International Primary Care Airways Group (IPAG) Diagnostic and Treatment Handbook and is widely used worldwide. However, Kawayama et al reported that the specificity of the IPAG questionnaire was very low for the Japanese population, with the initially proposed cutoff value of 16.5 points. ${ }^{15}$ Stanley et al noted that the best cutoff value for the IPAG questionnaire in Australia was 19.5 points. ${ }^{16}$ The COPD-Population Screener (COPD-PS), a simple five-item screening questionnaire developed in the United States in 2008, had a cutoff value of five points for the Americans. ${ }^{17}$ Similarly, the best cutoff value of COPD-PS was four points for the Japanese. ${ }^{18,19}$ Therefore, since the optimal cutoff value of the questionnaire differs in each country, an optimal questionnaire for the Japanese population is required. In 2017, a simplified screening questionnaire (COPD-Q, COPD Screening Questionnaire) was developed for the Japanese population and was expected to be useful as a COPD screening tool for the Japanese society. ${ }^{20}$

For lung cancer diagnosis, low-dose computed tomography (CT) screening has been used, which is more invasive than questionnaires. Early diagnosis with $\mathrm{CT}$ screening led to a reduction in deaths due to lung cancer, in the National Lung Screening Trial, which compared low-dose CT with chest X-rays ${ }^{21}$ and in the NELSON study, which compared randomized groups of low-dose CT screening and no screening and followed them up for 10 years. $^{22}$ In Japan, although low-dose CT screening has been shown to be effective in reducing lung cancer mortality, ${ }^{23,24} \mathrm{CT}$ screening is still performed on a voluntary basis. Mets et al showed that CT emphysema, CT air trapping, and CT bronchial wall thickening detected by CT screening for lung cancer independently contribute to COPD diagnosis. ${ }^{25}$ Therefore, the data from CT screening is expected to be useful in screening for COPD. Although there have been many reports on the use of respiratory function tests and questionnaires for creating COPD questionnaires, there have been no reports on the effectiveness of questionnaires using CT screening data.

The Division of Medical Oncology \& Respiratory Medicine, Shimane University Faculty of Medicine and Japan Agricultural Cooperatives Shimane Koseiren have been conducting voluntary low-dose chest CT screening for the early detection of lung cancer and COPD since 2009, and patients have been asked to fill out a questionnaire based on the IPAG questionnaire for collecting clinical data. This study aims to retrospectively evaluate the validity of the IPAG questionnaire for the Japanese and to propose a useful COPD-screening questionnaire adapted to the Japanese population using the CT screening data in Shimane, Japan.

\section{Patients and Methods Low-Dose CT Screening in Shimane, Japan}

The protocol for CT screening in Shimane, Japan is shown in Figure 1. The Japan Agricultural Cooperatives Shimane Koseiren recommended CT screening for adults over 40 years of age living in Shimane Prefecture. The screening was optional, and CT examination was performed on adults under 40 years of age upon request.

Participants completed a medical questionnaire (Figure 2) and underwent low-dose CT examination using a car-mounted 4-row multi-slice CT ECLOS (5 mm slice thickness) (Hitachi, Ltd., Hitachi, Japan). The imaging conditions were $120 \mathrm{kV}$ tube voltage and $50 \mathrm{~mA}$ tube current. All CT images were analyzed and interpreted by two respiratory physicians from Shimane University. The examination results were classified as "no abnormality", "follow-up", or "needed examination" by the examining physician. Non-calcified nodules with a diameter of $\geq 6 \mathrm{~mm}$ were picked up and required further examination for suspected lung cancer. In the case of emphysema, a participant with a history of smoking and respiratory symptoms on the medical questionnaire was considered as "needed examination for suspected 


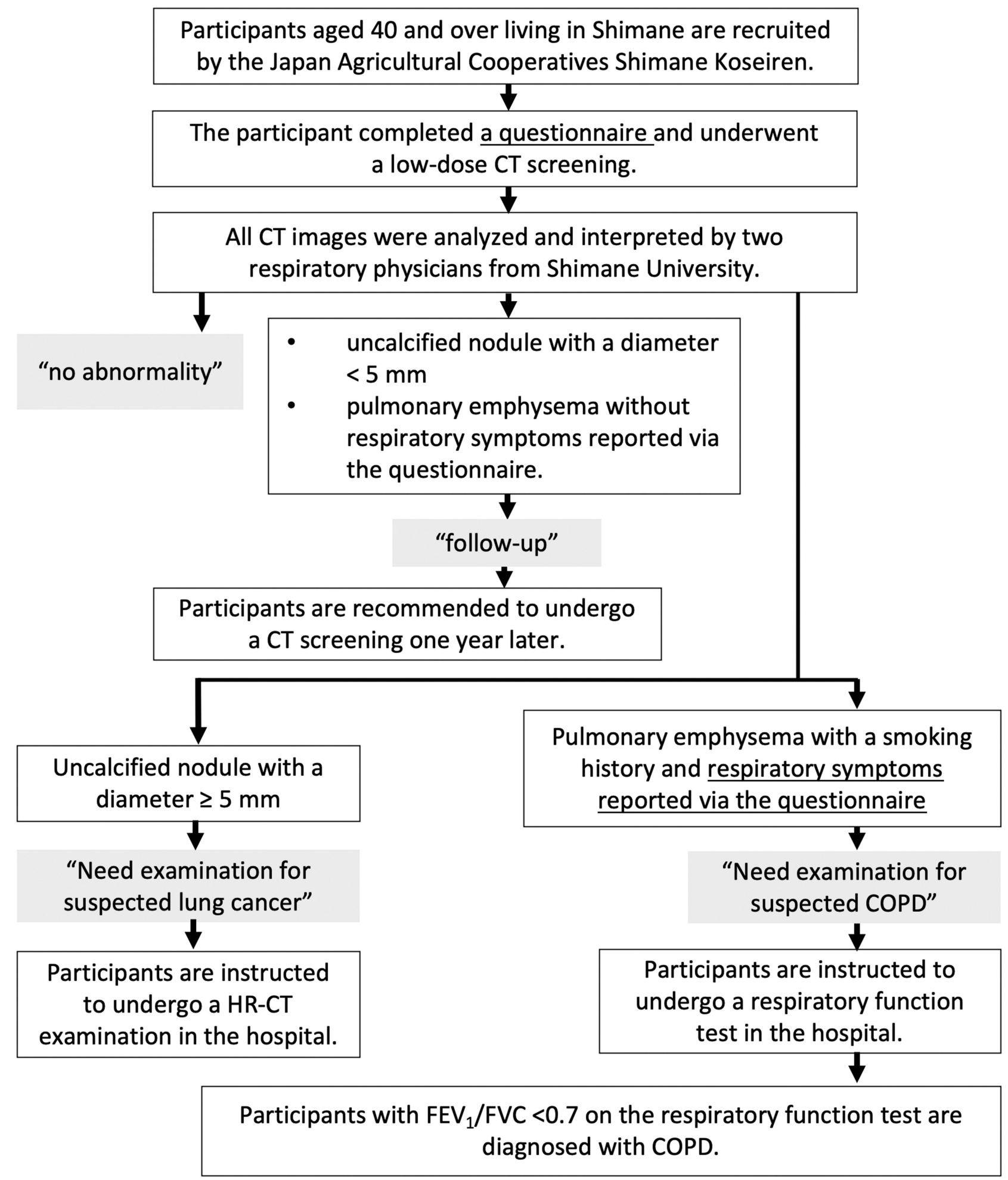

Figure I Protocol for CT screening in Shimane, Japan.

Abbreviations: COPD, chronic obstructive pulmonary disease; CT, computed Tomography; HR-CT, high resolution computed tomography; FEV $\mathrm{I}_{\mathrm{l}}$, forced expiratory volume in one second; FVC, forced vital capacity. 


\begin{tabular}{|c|c|c|c|}
\hline & Items & Response categories & $\begin{array}{l}\text { IPAG } \\
\text { questionnaire } \\
\text { items }\end{array}$ \\
\hline Q1 & age, height, weight & years, $\mathrm{cm}, \mathrm{kg}$ & $\checkmark$ \\
\hline Q2 & Smoking intensity, pack-years & $\begin{array}{l}\text { current (pack-years) } \\
\text { former (pack-years) } \\
\text { never }\end{array}$ & $\checkmark$ \\
\hline Q3 & $\begin{array}{l}\text { Are there smokers around you? (Are you exposed to passive } \\
\text { smoking?) }\end{array}$ & yes/no & \\
\hline Q4 & Have you ever had a lung disease? & yes/no (Details) & \\
\hline Q5 & Are you currently being treated for any disease? & yes/no (Details) & \\
\hline Q6 & $\begin{array}{l}\text { Have you previously received treatment for any diseases other } \\
\text { than respiratory disease? }\end{array}$ & yes/no (Details) & \\
\hline Q7 & Have you ever had chest surgery? & yes/no (Details) & \\
\hline Q8 & $\begin{array}{l}\text { Have you ever worked in a workplace where you inhale dust such } \\
\text { as asbestos? }\end{array}$ & yes/no (Details) & \\
\hline Q9 & Have you had respiratory symptoms within the last 6 months? & $\begin{array}{l}\text { (1) no, (2) cough, (3) bloody sputum, } \\
\text { (4) sputum, (5) chest pain, } \\
\text { (6) hoarseness, (7) feeling of dyspnea }\end{array}$ & \\
\hline Q10 & $\begin{array}{l}\text { Do you have shortness of breath when you climb stairs or } \\
\text { slopes? }\end{array}$ & yes/no & \\
\hline Q11 & Does the weather affect your cough? & yes/no & $\checkmark$ \\
\hline Q12 & $\begin{array}{l}\text { Do you ever cough up phlegm (sputum) from your chest when } \\
\text { you don't have a cold? }\end{array}$ & yes/no & $\checkmark$ \\
\hline Q13 & $\begin{array}{l}\text { Do you usually cough up phlegm (sputum) from your chest first } \\
\text { thing in the morning? }\end{array}$ & yes/no & $\checkmark$ \\
\hline Q14 & How frequently do you wheeze? & occasionally or more often/never & $\checkmark$ \\
\hline Q15 & Do you have or have you had any allergies? & yes/no & $\checkmark$ \\
\hline
\end{tabular}

Figure 2 Questionnaire created by our department and used for CT screening in Shimane, Japan. IPAG questionnaire items represent the interview questions that are the same as in the IPAG questionnaire.

Abbreviation: IPAG, International Primary Care Airways Group.

COPD." The presence of emphysema was determined by visual examination by a respiratory physician.

The results of the CT examination were mailed to all the participants, and the "follow-up" cases were recommended for a repeat $\mathrm{CT}$ examination after one year. The participants who "needed examination for suspected lung cancer" and "needed examination for suspected COPD" were introduced to a hospital with a respiratory specialist. Participants who "needed examination for suspected COPD" were instructed to perform a respiratory function test in the hospital. Participants with $\mathrm{FEV}_{1} / \mathrm{FVC}<0.7$ on the respiratory function test, were diagnosed with COPD. However, the use of bronchodilators in respiratory function tests was not considered. Several participants who were diagnosed with COPD during the examination still returned for lung cancer screening. The participants who were diagnosed with COPD and on active treatment will not be considered as "needed examination for suspected COPD" even if the patients have emphysema or respiratory symptoms.

\section{Questionnaire for CT Screening}

The questionnaire (Figure 2) was based on the IPAG questionnaire with eight items (questions 3 to 10) prepared by our department members. Questions pertaining to the history of pulmonary disease, comorbidities, history of thoracic surgery, and history of dust exposure were answered as "yes" or "no", followed by detailed disease names. Question 9: "Have you had respiratory symptoms within the last six months?" included six chest-related symptoms: cough, blood clot, phlegm, chest pain, hoarseness, and feeling of dyspnea. In addition, an item was added for the shortness of breath on exertion question "Do you have shortness of breath when you climb stairs 
or slopes?" based on the Medical Research Council shortness of breath scale. ${ }^{26,27}$ If questions $9,10,11,12,13$, or 14 were applicable, the participant was determined to have "respiratory symptoms".

\section{Study Population}

The study included 11,620 participants who lived in Shimane and underwent low-dose CT screening during a 4-year period (2013-2016). The cumulative number of patients includes those who underwent CT screening multiple times in this study. Data from 162 participants diagnosed with COPD but who returned for CT screening were excluded. Therefore, the data from 11,458 participants were considered.

The present study was a database-based retrospective study, and the study protocol was approved by the Ethics Committee of Shimane University Faculty of Medicine and Japan Agricultural Cooperatives Shimane Koseiren. The study was conducted in accordance with the Declaration of Helsinki (as revised in 2013). This retrospective study was approved by the Institutional Review Board (approval number: 4543), and the requirement for informed consent was waived due to the retrospective nature of the study. A summary of the study was posted on the institution's website, all subjects were provided the opportunity to refuse to participate in the study. None of the subjects refused to participate in the study.

\section{Statistical Analysis}

CT screening in Shimane Prefecture included nonsmoking participants under the stipulated age of 40 years. These are groups with a low pre-test positivity rate for which screening is not recommended because of their inherently low risk of developing lung cancer or COPD. ${ }^{28,29}$ Therefore, to improve the quality of the sample, except for the rare positive group, "pack-year" was considered, which is particularly relevant to $\mathrm{COPD}, 3,6$ and the data were examined. For the 11,458 individuals in the sample, the receiver operating characteristic (ROC) curves were determined for pack-years $(\mathrm{n}=$ $11,458)$ to determine the best cutoff pack-year for COPD diagnosis (Figure 3). The point with the largest area under the curve was taken as the best cutoff value. The best cutoff value of 22.5 pack-years showed a sensitivity and specificity of $91.3 \%$ and $73.0 \%$, respectively. Therefore, the participants were classified into two groups: "pack-years of $<22.5$ " and "pack-years of $\geq 22.5$ " (Table 1). Among the 8206 participants in the "pack-years of $<22.5$ ", only 21 participants $(0.26 \%)$ were diagnosed with COPD, and these data resulted in mostly negative findings. Therefore, the data for

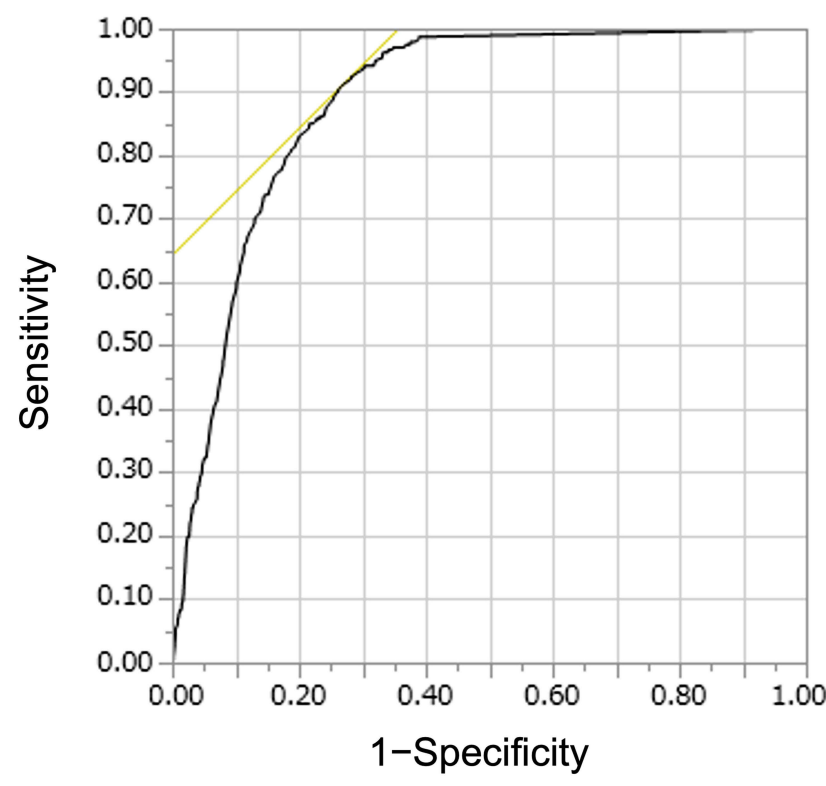

Figure 3 ROC curve for pack-year (sample, $\mathrm{n}=1 \mathrm{I}, 458$ ). Area under ROC curve = 0.88588 . A cut-off of 22.50 pack-year showed a sensitivity of $91.3 \%$ and a specificity of $73.0 \%$.

Abbreviation: ROC, receiver operating characteristic.

"pack-years of $<22.5$ " were excluded, and 3252 participants were selected with a COPD prevalence of $6.77 \%$ (packyears of $\geq 22.5$ ) for the subsequent analysis.

ROC curve analysis was performed with the IPAG questionnaire as an explanatory variable $(n=3252)$. The point with the largest area under the curve was used as the cutoff value.

All statistical analyses were performed using JMP 12.01 (SAS Institute Inc., Cary, NC, USA). Results were considered statistically significant at $P<0.05$.

\section{Results}

\section{Participants' Characteristics}

The detection rates for lung cancer and COPD were $0.37 \%$ and $2.26 \%$, respectively, for all the screening participants

Table I Relationship Between Pack-Years and COPD Occurrence

\begin{tabular}{|l|c|c|c|}
\hline & $\begin{array}{c}\text { Pack- } \\
\text { Year }< \\
\mathbf{2 2 . 5 0}\end{array}$ & $\begin{array}{c}\text { Pack- } \\
\text { Year } \geq \\
\mathbf{2 2 . 5 0}\end{array}$ & Total \\
\hline Participants & 8206 & 3252 & $1 \mathrm{I}, 458$ \\
\hline $\begin{array}{l}\text { Participants with "needed } \\
\text { examination for suspected COPD" } \\
\text { (\% of group) }\end{array}$ & $\begin{array}{c}50 \\
(0.6 \mathrm{I})\end{array}$ & $\begin{array}{c}410 \\
(12.6)\end{array}$ & $\begin{array}{c}460 \\
(4.01)\end{array}$ \\
\hline $\begin{array}{l}\text { Participants diagnosed with COPD } \\
\text { (\% of group) }\end{array}$ & $\begin{array}{c}21 \\
(0.26)\end{array}$ & $\begin{array}{c}220 \\
(6.77)\end{array}$ & $\begin{array}{c}24 \mathrm{I} \\
(2.10)\end{array}$ \\
\hline
\end{tabular}

Abbreviation: COPD, chronic obstructive pulmonary disease. 
$(\mathrm{n}=11,620)$ from 2013 to 2016 . The baseline characteristics of the 3252 participants are presented in Table 2. All the participants in our study were over 40 years of age and had a smoking history. These characteristics were similar to those reported in previous studies involving the IPAG questionnaire (Supplementary Table S1) ${ }^{13,14}$

\section{Validity of the IPAG Questionnaire}

Next, the ROC curve analysis for IPAG score determined the cutoff value of 23 , with a sensitivity and specificity of $60.4 \%$ and $63.8 \%$, respectively (Figure 4). In contrast, with the IPAG cutoff value of 17 applied to the data, the sensitivity was high (97.7\%), but the specificity was low (13.6\%) (Figure 4). Therefore, the best cutoff point for the Japanese population was considered as 23 .

\section{Questionnaire Item Selection}

The efficacy of the questionnaire components for screening COPD was analyzed by logistic regression analysis (Table 3). The analysis revealed significant differences in "age (Q1)", "pack-years (Q2)", "Do you often develop cough? (Q9-2)", "Do you often produce sputum? (Q9-4)", and "Do you often have a feeling of dyspnea? (Q9-7)". We named the novel COPD screening questionnaire based on CT screening data, including these five items, "COPD-CT."

Furthermore, we used the logistic regression model to determine the COPD predicted value. Assuming that patient responses to the questions "Do you often develop cough?", "Do you often produce sputum?", and "Do you often have a feeling of dyspnea?" were all "yes", Table 4 shows the COPD predicted values that were calculated based on the patient responses relating to "age" and "packyears". According to Table 4, COPD predicted value was $44.2 \%$ when the target age and pack-years were 80 and 60 , respectively. Also, Table 5 shows the predicted values when the response to only "Do you often have a feeling of dyspnea?" was "yes". For example, when the target age and pack-years were 80 and 60 respectively, the COPD predicted value was $17.7 \%$. Likewise, COPD predicted values with combinations of the other three symptoms ("Do you often develop cough?", "Do you often produce sputum?", and "Do you often have a feeling of dyspnea?") were presented in six tables (Supplementary Tables $\underline{\mathrm{S} 2-\mathrm{S} 7)}$.

\section{Discussion}

In this study, the validity of the IPAG questionnaire using the CT screening data was examined in Shimane, Japan.
Table 2 Baseline Characteristics of the Subjects and All Participants

\begin{tabular}{|c|c|c|}
\hline Characteristics & Subjects & $\begin{array}{c}\text { All } \\
\text { Participants }\end{array}$ \\
\hline Participants & 3252 & 11,458 \\
\hline \multicolumn{3}{|l|}{ Sex } \\
\hline Male (\%) & $3120(95.94)$ & $6186(53.99)$ \\
\hline Female (\%) & $132(4.06)$ & $5272(46.01)$ \\
\hline Mean age (median) & $64.17(65.00)$ & $64.69(66.00)$ \\
\hline \multicolumn{3}{|l|}{ Age categories } \\
\hline$<40$ years $(\%)$ & I $(0.03)$ & $71(0.62)$ \\
\hline $40-49$ years (\%) & $262(8.06)$ & $1060(9.25)$ \\
\hline $50-59$ years (\%) & $678(20.85)$ & $1944(16.97)$ \\
\hline $60-69$ years $(\%)$ & $1382(42.50)$ & $4490(39.19)$ \\
\hline $70-79$ years $(\%)$ & $798(24.54)$ & $325 I(28.37)$ \\
\hline$\geqq 80$ years $(\%)$ & $|3|(4.03)$ & $642(5.60)$ \\
\hline \multicolumn{3}{|l|}{ Smoking status } \\
\hline Mean pack-year (median) & $43.33(39.75)$ & $14.0 \mid(0.00)$ \\
\hline \multicolumn{3}{|l|}{ Former or current smoker } \\
\hline 0 to $<20$ pack-years (\%) & $0(0.00)$ & $7911(69.04)$ \\
\hline 20 to $<30$ pack-years (\%) & $636(19.56)$ & $931(8.13)$ \\
\hline 30 to $<40$ pack-years (\%) & $996(30.63)$ & $996(8.69)$ \\
\hline 40 to $<50$ pack-years (\%) & $785(24.14)$ & $785(6.85)$ \\
\hline$\geqq 50$ pack-years (\%) & $835(25.68)$ & $835(7.29)$ \\
\hline Total smokers (\%) & $3252(1.00)$ & 4817 (42.07) \\
\hline Mean BMI (median) & $23.35(23.10)$ & $23.00(22.77)$ \\
\hline \multicolumn{3}{|l|}{ BMI categories } \\
\hline$<22 \%(\%)$ & $1078(33.14)$ & 4419 (38.57) \\
\hline 22 to $<25.4$ (\%) & $1423(43.76)$ & $4798(41.87)$ \\
\hline 25.4 to $<29.7$ (\%) & $654(20.11)$ & $1928(16.83)$ \\
\hline$\geqq 29.7$ (\%) & $97(2.98)$ & $313(2.73)$ \\
\hline Mean IPAG score (median) & $21.49(22.00)$ & $18.83(19.00)$ \\
\hline \multicolumn{3}{|l|}{ IPAG score categories } \\
\hline$<17(\%)$ & $417(12.82)$ & $3138(27.38)$ \\
\hline 17 to $<23$ (\%) & $1605(49.35)$ & $6523(56.92)$ \\
\hline 23 to $<30(\%)$ & $1123(34.53)$ & $1686(14.71)$ \\
\hline$\geqq 30$ (\%) & $107(3.29)$ & III (0.96) \\
\hline Positive screening result (COPD) & $410(12.60)$ & $460(4.01)$ \\
\hline COPD (\%) & $220(6.77)$ & $24 \mid(2.10)$ \\
\hline $\begin{array}{l}\text { Positive screening result (lung } \\
\text { cancer) }\end{array}$ & $158(4.85)$ & $443(3.86)$ \\
\hline Lung cancer (\%) & $22(0.67)$ & $43(0.37)$ \\
\hline
\end{tabular}

Abbreviations: IPAG, International Primary Care Airways Group; BMI, body mass index; COPD, chronic obstructive pulmonary disease.

The best cutoff points were found to be 23 for the Japanese population. Furthermore, a logistic regression analysis of the original questionnaire was performed to narrow down 


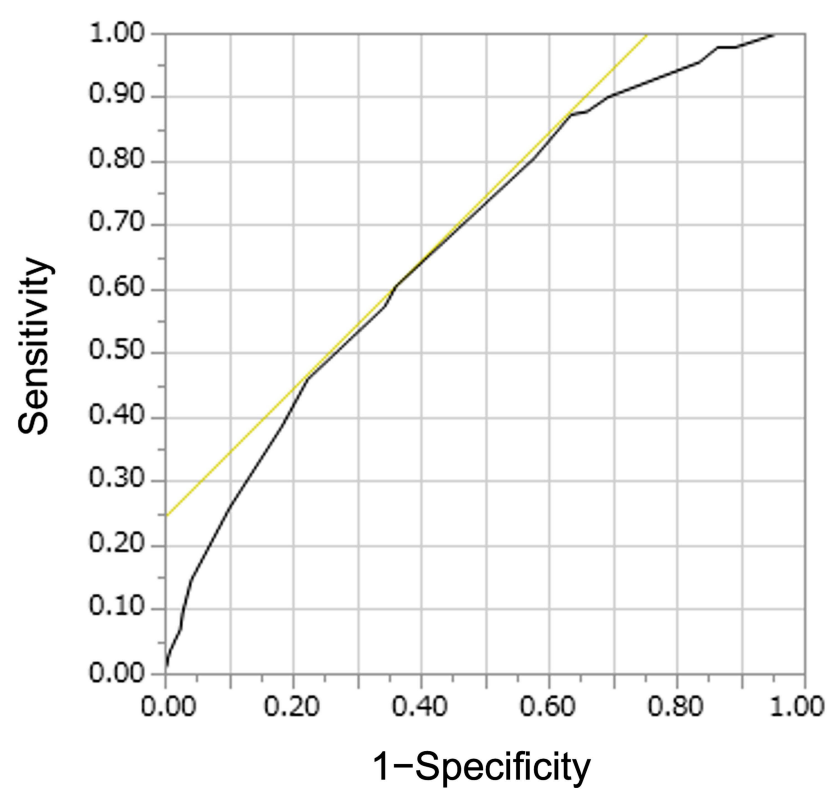

Figure 4 ROC curve for the COPD questionnaire of IPAG (subset sample, $\mathrm{n}=$ 3252). Area under ROC curve $=0.67648$. A cut-off score of 23.00 showed a sensitivity of $60.4 \%$ and a specificity of $63.8 \%$.

Abbreviations: ROC, receiver operating characteristic; COPD, chronic obstructive pulmonary disease; IPAG, International Primary Care Airways Group.

the five items (age, pack-year, coughing, sputum, and feeling of dyspnea) that were useful for COPD screening. Finally, the COPD-CT questionnaire and the logistic regression model for the COPD predicted value, based on the CT screening data, were proposed.

The IPAG questionnaire was developed and scored from a population from the UK and USA with a mean

Table 3 Efficacy of the Components of the Novel Questionnaire Used to Screen for COPD in Shimane, Japan

\begin{tabular}{|c|c|c|c|c|}
\hline & Item & $\begin{array}{l}\text { Response } \\
\text { Categories }\end{array}$ & $\begin{array}{l}\text { Odds } \\
\text { Ratio }\end{array}$ & $P$ value \\
\hline 1 & Age (QI) & & - & 0.0051 \\
\hline 2 & $\begin{array}{l}\text { Smoking status (pack-year) } \\
\text { (Q2) }\end{array}$ & $\begin{array}{c}\text { Current } \\
\text { (pack-year) } \\
\text { Former } \\
\text { (pack-year) } \\
\text { Never }\end{array}$ & - & $<0.0001$ \\
\hline 3 & $\begin{array}{l}\text { Do you often develop } \\
\text { cough? (Q9-2) }\end{array}$ & Yes/no & 1.86 & 0.0004 \\
\hline 4 & $\begin{array}{l}\text { Do you often produce } \\
\text { sputum? (Q9-4) }\end{array}$ & Yes/no & 1.98 & 0.0001 \\
\hline 5 & $\begin{array}{l}\text { Do you often have a feeling } \\
\text { of dyspnea? (Q9-7) }\end{array}$ & Yes/no & 2.19 & 0.0023 \\
\hline
\end{tabular}

age of 58 years and a mean BMI of $28 .^{13,14}$ In this study, based on an IPAG cutoff of 17, 2835 of the 3252 participants $(87.1 \%)$ were suspected to have COPD (Table 2). The older the patient, higher the IPAG score. Also, lower the BMI, higher the IPAG score. The Japanese have a longer life expectancy ${ }^{30}$ and lower average weight ${ }^{31}$ than Westerners, so their average IPAG score should be higher than that of Westerners. However, it is known that the COPD prevalence among Japanese is similar to or less than that among the Western population., ${ }^{2,5}$ Therefore, for the Japanese, the IPAG questionnaire may be too sensitive for screening, because the distribution of points for age and BMI is too large. In summary, our study also highlighted the desirability of using a questionnaire that is appropriate for the target population.

The results from the logistic regression analysis showed that the patients with clinical findings of old age, high pack-years, cough, sputum, and dyspnea were more likely to have COPD. Particularly, "dyspnea" symptom was not included in the IPAG questionnaire; however, other COPD screening tools such as COPDPS, ${ }^{17}$ 11-Q, ${ }^{32}$ COPD-Q, ${ }^{20}$ and PUMA scores, ${ }^{33}$ have included dyspnea symptom. Moreover, previous reports have shown efficacy for the "dyspnea" symptom. ${ }^{34}$ Thus, dyspnea symptoms should be given importance during COPD screening.

We successfully obtained the COPD predicted value based on the questionnaire items, age, and pack-years. Because the prevalence of COPD in this study $(\mathrm{n}=3252)$ was $6.77 \%$, COPD predicted values more than $6.77 \%$ were considered higher than average. Therefore, we believe that the possibility of COPD was high when the COPD predicted value exceeded $6.77 \%$. Furthermore, a combination of the items, which have high predictive values, could be chosen from the tables to match the purpose of each screening. The most similar study to ours is the COPD- $Q^{20}$ questionnaire, which was designed for detecting persistent airflow obstruction (AO) in 2338 Japanese patients. In the COPD-Q questionnaire, items related to cough and sputum were grouped as "How often do you cough up phlegm when you are not sick?" Additionally, the COPD-Q questionnaire differs from the COPD-CT questionnaire in that "wheezing on exertion" was added to the questionnaire item. The COPD-Q simply predicts the presence or absence of AO as exceeding the cutoff value of four points. In contrast, the COPD-CT shows each participant's COPD predicted value, which can be considered to be more individualized than the COPD-Q. 
Table 4 COPD Predicted Value Calculated Using the Logistic Regression Model Obtained in This Study. It is Assumed That Responses to the Questions “Do You Often Develop Cough?", “Do You Often Produce Sputum?”, and “Do You Often Have a Feeling of Dyspnea?" are All "Yes"

\begin{tabular}{|l|c|c|c|c|c|c|c|c|c|}
\hline \multicolumn{2}{|c|}{ COPD Predicted Value (\%) } & \multicolumn{9}{c|}{ Pack-Year } \\
\cline { 3 - 9 } \multicolumn{2}{|c|}{} & $\mathbf{3 0}$ & $\mathbf{4 0}$ & $\mathbf{5 0}$ & $\mathbf{6 0}$ & $\mathbf{7 0}$ & $\mathbf{8 0}$ & $\mathbf{9 0}$ & $\mathbf{1 0 0}$ \\
\hline \multirow{2}{*}{ Age } & 40 & 14.9 & 17.4 & 20.3 & 23.4 & 26.9 & 30.7 & 34.7 & 39.0 \\
& 50 & 18.2 & 21.2 & 24.4 & 28.0 & 31.8 & 35.9 & 40.3 & 44.8 \\
& 60 & 22.1 & 25.4 & 29.0 & 33.0 & 37.2 & 41.6 & 46.1 & 50.7 \\
& 70 & 26.4 & 30.2 & 34.2 & 38.5 & 42.9 & 47.5 & 52.1 & 56.7 \\
& 80 & 31.3 & 35.4 & 39.7 & 44.2 & 48.8 & 53.4 & 58.0 & 62.4 \\
& 90 & 36.6 & 41.0 & 45.6 & 50.2 & 54.8 & 59.3 & 63.6 & 67.8 \\
\hline
\end{tabular}

Abbreviation: COPD, chronic obstructive pulmonary disease.

Table 5 COPD Predicted Value Calculated Using the Logistic Regression Model Obtained in This Study. It is Assumed That Response to the Questions "Do You Often Have a Feeling of Dyspnea?", Which Has the Highest Odds Ratio Among the Narrowed Questionnaires, is "Yes"

\begin{tabular}{|l|c|c|c|c|c|c|c|c|c|}
\hline \multicolumn{2}{|c|}{ COPD Predicted Value (\%) } & \multicolumn{9}{c|}{ Pack-Year } \\
\cline { 3 - 9 } \multicolumn{2}{|c|}{} & $\mathbf{3 0}$ & $\mathbf{4 0}$ & $\mathbf{5 0}$ & $\mathbf{6 0}$ & $\mathbf{7 0}$ & $\mathbf{8 0}$ & $\mathbf{9 0}$ & 100 \\
\hline \multirow{2}{*}{ Age } & 40 & 5.0 & 5.4 & 6.5 & 7.7 & 9.1 & 10.7 & 12.6 & 14.8 \\
& 50 & 5.7 & 6.8 & 8.1 & 9.5 & 11.2 & 13.2 & 15.5 & 18.1 \\
& 60 & 7.1 & 8.5 & 10.0 & 11.8 & 13.9 & 16.2 & 18.9 & 21.9 \\
& 70 & 8.9 & 10.5 & 12.4 & 14.5 & 16.9 & 19.7 & 22.8 & 26.2 \\
& 80 & 11.0 & 13.0 & 15.2 & 17.7 & 20.6 & 23.7 & 27.3 & 31.1 \\
& 90 & 13.6 & 15.9 & 18.5 & 21.5 & 24.7 & 28.3 & 32.2 & 36.4 \\
\hline
\end{tabular}

Abbreviation: COPD, chronic obstructive pulmonary disease.

In this study, the number of patients was narrowed down before the analysis. The prevalence of COPD was initially low at $2.1 \%$ for all the 11,428 participants, and it increased to $6.7 \%$ after narrowing down the data, which is close to the COPD prevalence of $8.6 \%$ reported previously in a large Japanese epidemiological study. ${ }^{5}$ Therefore, the narrowed 3252-sample data were considered to retain the general Japanese characteristics and increased accuracy for the subsequent analysis.

The study has a few limitations. First, the determination of emphysema, based on the CT screening data used as a sample, was made by the physician and was a subjective assessment. The low attenuation area (LAA) of emphysema is often scored using the Goddard method ${ }^{35}$ or assessed using automated analysis software. ${ }^{36}$ However, the CT screening indicates emphysema as "present" or "absent", which is a subjective binary assessment and may cause problems with variability in assessment between different observers. However, quantitative and qualitative evaluation of emphysema has been reported to be possible with low-dose CT imaging. ${ }^{37-39}$ In this screening, the presence of even a small amount of emphysema was judged as "emphysema present," so the screening sensitivity was believed to be preserved. In future studies, it will be necessary to consider not only subjective visual evaluation but also quantitative evaluation of LAA using automated analysis software. Second, COPD is generally classified into "emphysema type" and "bronchial type". ${ }^{40,41}$ In our study, only those participants who had emphysema on CT were considered as "needed examination for suspected COPD". Therefore, the bronchial type of COPD may not have been diagnosed. If the screening for the "emphysema type" COPD was feasible, the number of final COPD diagnosed cases was not significantly affected, and the accuracy of the data sample was preserved since emphysema type COPD is more common than bronchial type COPD in Japan. ${ }^{42}$ Third, in this study, participants who had emphysema and had a history of smoking and respiratory symptoms on the questionnaire were referred to their local hospitals. Since respiratory function tests were performed at the discretion of the respiratory physicians at each facility, participants 
without prior use of bronchodilators were included. Therefore, participants with bronchial asthma may be included among the participants diagnosed with COPD in this study. A retrospective study, including 14,056 participants with $69 \%$ of smokers, revealed that $8.1 \%$ of all participants had $\mathrm{FEV}_{1} / \mathrm{FVC}<0.7$, which recovered after using bronchodilators. ${ }^{28}$ However, in this study, only the participants who were smokers, had respiratory symptoms, and had CT emphysema underwent respiratory function tests. Therefore, we expected that the participants with non-ACO asthma were much less than $8.1 \%$, which has almost no impact on the COPD predicted value.

The COPD-CT and the COPD predicted value developed in our study can be used widely by respiratory specialists and general internists as a screening method for COPD. Even without a spirometer, suspected COPD cases can be easily detected in clinics at an early stage, and the suspected patients can be referred to a hospital. The COPD-CT and the COPD predicted value can also be useful for smoking cessation in clinics. Patients can be motivated to quit smoking by showing them the decrease in the COPD predicted value on reducing the cigarettes smoked to a certain number. We also believe that the COPD-CT and the COPD predicted value developed in our study will help improve the accuracy of CT screening.

Future studies will involve conducting research to further enhance the model by comparing the COPD predicted value and the actual result of CT screening evaluation by physicians. Data pertaining to emphysema cases with low COPD predicted values can be collected. A trained physician may diagnose emphysema in these rare cases. By finding a common factor among the cases, a novel factor could be found, which needs to be included in our next model. In addition, these cases could be useful for untrained physicians for learning screening skills.

Although we only collected binary data on whether the $\mathrm{FEV}_{1} / \mathrm{FVC}$ was above or below 0.7 (COPD or not) in participants who underwent respiratory function tests until 2015, we have been collecting numerical data on $\mathrm{FEV}_{1}, \mathrm{FEV}_{1}$ /FVC, and \% predicted $\mathrm{FEV}_{1}$ from 2016, which will allow us to analyze the severity of COPD. Thus, we plan to refine the questionnaire using the database with the addition of COPD severity and examine how effective the questionnaire using $\mathrm{CT}$ screening data is in screening for early/mild COPD.

\section{Conclusion}

The IPAG questionnaire had low specificity as a COPD screening questionnaire for Japanese participants. A novel COPD-CT questionnaire and the COPD predicted value was proposed, which is based on the logistic regression analysis of CT screening data in Shimane, Japan.

\section{Acknowledgments}

We thank Shinji Ishikura and Kaoru Mikajiri from the Japan Agricultural Cooperatives Shimane Koseiren for their assistance with the CT screening. The authors thank the participants who underwent CT-screening for their contributions to this study.

\section{Funding}

The authors received no financial support for this study.

\section{Disclosure}

Dr Akari Tanino reports personal fees from Boehringer Ingelheim, outside the submitted work. Dr Ryosuke Tanino reports grants, personal fees from Boehringer Ingelheim, outside the submitted work. Dr Takeshi Isobe reports personal fees from AstraZeneca and Boehringer Ingelheim, outside the submitted work. The authors report no other conflicts of interest in this work.

\section{References}

1. Menezes AMB, Perez-Padilla R, Jardim JB, et al. Chronic obstructive pulmonary disease in five Latin American cities (the PLATINO study): a prevalence study. Lancet. 2005;366(9500):1875-1881. doi:10.1016/ S0140-6736(05)67632-5

2. Buist AS, McBurnie MA, Vollmer WM, et al. International variation in the prevalence of COPD (The BOLD Study): a population-based prevalence study. Lancet. 2007;370(9589):741-750. doi:10.1016/ S0140-6736(07)61377-4

3. Cigarette smoking and health. American Thoracic Society. Am J Respir Crit Care Med. 1996;153(2):861-865. doi:10.1164/ ajrccm.153.2.8564146

4. Terzikhan N, Verhamme KMC, Hofman A, Stricker BH, Brusselle GG, Lahousse L. Prevalence and incidence of COPD in smokers and non-smokers: the Rotterdam Study. Eur J Epidemiol. 2016;31(8):785-792. doi:10.1007/s10654-016-0132-Z

5. Fukuchi $Y$, Nishimura $M$, Ichinose $M$, et al. COPD in Japan: the Nippon COPD Epidemiology study. Respirology. 2004;9(4):458-465. doi:10.1111/j.1440-1843.2004.00637.x

6. Lundbäck B, Lindberg A, Lindström M, et al. Not 15 but $50 \%$ of smokers develop COPD?-Report from the obstructive lung disease in Northern Sweden Studies. Respir Med. 2003;97(2):115-122. doi:10.1053/rmed.2003.1446

7. Smith M, Wrobel J. Epidemiology and clinical impact of major comorbidities in patients with COPD. Int J Chron Obstruct Pulmon Dis. 2014;871. doi:10.2147/COPD.S49621

8. Mannino DM, Aguayo SM, Petty TL, Redd SC. Low lung function and incident lung cancer in the United States: data from the first national health and nutrition examination survey follow-up. Arch Intern Med. 2003;163(12):1475. doi:10.1001/archinte.163.12.1475

9. Young RP, Hopkins RJ, Christmas T, Black PN, Metcalf P, Gamble GD. COPD prevalence is increased in lung cancer, independent of age, sex and smoking history. Eur Respir J. 2009;34 (2):380-386. doi:10.1183/09031936.00144208 
10. Takahashi T, Ichinose M, Inoue H, Shirato K, Hattori T, Takishima T. Underdiagnosis and undertreatment of COPD in primary care settings. Respirology. 2003;8(4):504-508. doi:10.1046/j.14401843.2003.00501.x

11. Anthonisen N, Dik N, Manfreda J, Roos L. Spirometry and obstructive lung disease in Manitoba. Can Respir J. 2001;8(6):421-426. doi:10.1155/2001/572825

12. Haroon SM, Jordan RE, O'Beirne-Elliman J, Adab P. Effectiveness of case finding strategies for COPD in primary care: a systematic review and meta-analysis. Npj Prim Care Respir Med. 2015;25 (1):15056. doi:10.1038/npjpcrm.2015.56

13. Price DB, Tinkelman DG, Nordyke RJ, Isonaka S, Halbert RJ. Scoring system and clinical application of COPD diagnostic questionnaires. Chest. 2006;129(6):1531-1539. doi:10.1378/chest.129.6.1531

14. Price DB, Tinkelman DG, Halbert RJ, et al. Symptom-based questionnaire for identifying COPD in smokers. Respiration. 2006;73 (3):285-295. doi:10.1159/000090142

15. Kawayama T, Minakata Y, Matsunaga K, et al. Validation of symptom-based COPD questionnaires in Japanese subjects. Respirology. 2008;13(3):420-426. doi:10.1111/j.1440-1843.2008.01241.x

16. Stanley AJ, Hasan I, Crockett AJ, van Schayck OC, Zwar NA. Validation of the COPD diagnostic questionnaire in an Australian general practice cohort: a cross-sectional study. Prim Care Respir J. 2014;23(1):92-97. doi:10.4104/pcrj.2014.00015

17. Martinez FJ, Raczek AE, Seifer FD, et al. Development and initial validation of a self-scored COPD Population Screener Questionnaire (COPD-PS). J Chronic Obstr Pulm Dis. 2008;5(2):85-95. doi:10.1080/15412550801940721

18. Tsukuya G, Matsumoto K, Fukuyama S, et al. Validation of a COPD screening questionnaire and establishment of diagnostic cut-points in a Japanese general population: the Hisayama study. Allergol Int. 2015;64(1):49-53. doi:10.1016/j.alit.2014.06.002

19. Inoue H, Tsukuya G, Samukawa T, et al. Comparison of the COPD population screener and international primary care airway group questionnaires in a general Japanese population: the Hisayama study. Int J Chron Obstruct Pulmon Dis. 2016;11:1903-1909. doi:10.2147/COPD.S110429

20. Samukawa T, Matsumoto K, Tsukuya G, et al. Development of a self-scored persistent airflow obstruction screening questionnaire in a general Japanese population: the Hisayama study. Int J Chron Obstruct Pulmon Dis. 2017;12:1469-1481. doi:10.2147/COPD.S130453

21. The National Lung Screening Trial Research Team. Reduced lung-cancer mortality with low-dose computed tomographic screening. $N$ Engl J Med. 2011;365(5):395-409. doi:10.1056/ NEJMoa1102873

22. de Koning HJ, van der Aalst CM, de Jong PA, et al. Reduced lung-cancer mortality with volume CT screening in a randomized trial. $N$ Engl J Med. 2020;382(6):503-513. doi:10.1056/ NEJMoa1911793

23. Nawa T, Fukui K, Nakayama T, et al. A population-based cohort study to evaluate the effectiveness of lung cancer screening using low-dose CT in Hitachi city, Japan. Jpn J Clin Oncol. 2019;49 (2):130-136. doi:10.1093/jjco/hyy185

24. Nawa T. Low-dose CT screening for lung cancer reduced lung cancer mortality in Hitachi City. Int J Radiat Biol. 2019;95(10):1441-1446. doi:10.1080/09553002.2018.1511930

25. Mets OM, Schmidt M, Buckens CF, et al. Diagnosis of chronic obstructive pulmonary disease in lung cancer screening computed tomography scans: independent contribution of emphysema, air trapping and bronchial wall thickening. Respir Res. 2013;14(1):59. doi:10.1186/1465-9921-14-59

26. Celli BR, MacNee W, Agusti A, et al. Standards for the diagnosis and treatment of patients with COPD: a summary of the ATS/ERS position paper. Eur Respir J. 2004;23(6):932-946. doi:10.1183/ 09031936.04.00014304
27. Bestall JC, Paul EA, Garrod R, Garnham R, Jones PW, Wedzicha JA. Usefulness of the Medical Research Council (MRC) dyspnoea scale as a measure of disability in patients with chronic obstructive pulmonary disease. Thorax. 1999;54(7):581-586. doi:10.1136/ thx.54.7.581

28. Schermer TRJ, Smeele IJM, Thoonen BPA, et al. Current clinical guideline definitions of airflow obstruction and COPD overdiagnosis in primary care. Eur Respir J. 2008;32(4):945-952. doi:10.1183/ 09031936.00170307

29. Dela Cruz CS, Tanoue LT, Matthay RA. Lung cancer: epidemiology, etiology, and prevention. Clin Chest Med. 2011;32(4):605-644. doi:10.1016/j.ccm.2011.09.001

30. Kontis V, Bennett JE, Mathers CD, Li G, Foreman K, Ezzati M. Future life expectancy in 35 industrialised countries: projections with a Bayesian model ensemble. Lancet. 2017;389(10076):1323-1335. doi:10.1016/S0140-6736(16)32381-9

31. WHO. Global Health Observatory (GHO) data; overweight and obesity. Available from: https://www.who.int/data/gho/data/indica tors/indicator-details/GHO/mean-bmi-(kg-m-)-(age-standardizedestimate). Accessed June 2, 2021.

32. Kida K, Wakabayashi R, Mizuuchi T, Murata A. Screening for suspected chronic obstructive pulmonary disease with an eleven-item pre-interview questionnaire (11-Q). Intern Med. 2006;45(21):1201-1207. doi:10.2169/internalmedicine.45.1694

33. López Varela MV, Montes de Oca M, Rey A, et al. Development of a simple screening tool for opportunistic COPD case finding in primary care in Latin America: the PUMA study: COPD case finding in primary care. Respirology. 2016;21(7):1227-1234. doi:10.1111/ resp. 12834

34. Nishimura K, Izumi T, Tsukino M, Oga T. Dyspnea is a better predictor of 5-year survival than airway obstruction in patients with COPD. Chest. 2002;121(5):1434-1440. doi:10.1378/chest.121.5.1434

35. Goddard PR, Nicholson EM, Laszlo G, Watt I. Computed tomography in pulmonary emphysema. Clin Radiol. 1982;33(4):379-387. doi:10.1016/S0009-9260(82)80301-2

36. Coxson HO, Mayo J, Lam S, Santyr G, Parraga G, Sin DD. New and current clinical imaging techniques to study chronic obstructive pulmonary disease. Am J Respir Crit Care Med. 2009;180(7):588-597. doi:10.1164/rccm.200901-0159PP

37. Gierada DS, Pilgram TK, Whiting BR, et al. Comparison of standardand low-radiation-dose CT for quantification of emphysema. Am J Roentgenol. 2007;188(1):42-47. doi:10.2214/AJR.05.1498

38. Madani A, De Maertelaer V, Zanen J, Gevenois PA. Pulmonary emphysema: radiation dose and section thickness at multidetector CT quantification - comparison with macroscopic and microscopic morphometry. Radiology. 2007;243(1):250-257. doi:10.1148/ radiol.2431060194

39. Zaporozhan J, Ley S, Weinheimer O, et al. Multi-detector CT of the chest: influence of dose onto quantitative evaluation of severe Emphysema A Simulation Study. J Comput Assist Tomogr. 2006;30 (3):460-468. doi:10.1097/00004728-200605000-00018

40. Burrows B, Fletcher CM, Heard BE, Jones NL, Wootliff JS. The emphysematous and bronchial types of chronic airways obstruction. Lancet. $\quad$ 1966;287(7442):830-835. doi:10.1016/S0140-6736(66) 90181-4

41. Ogawa E, Nakano Y, Ohara T, et al. Body mass index in male patients with COPD: correlation with low attenuation areas on CT. Thorax. 2008;64(1):20-25. doi:10.1136/thx.2008.097543

42. Tatsumi K, Kasahara Y, Kurosu K, et al. Clinical phenotypes of COPD: results of a Japanese epidemiological survey. Respirology. 2004;9(3):331-336. doi:10.1111/j.1440-1843.2004.00611.x 


\section{Publish your work in this journal}

The International Journal of COPD is an international, peer-reviewed journal of therapeutics and pharmacology focusing on concise rapid reporting of clinical studies and reviews in COPD. Special focus is given to the pathophysiological processes underlying the disease, intervention programs, patient focused education, and self management protocols. This journal is indexed on PubMed Central, MedLine and CAS. The manuscript management system is completely online and includes a very quick and fair peer-review system, which is all easy to use. Visit http://www.dovepress.com/testimonials.php to read real quotes from published authors. 